\title{
Graphene Scaffolds Enhanced Photogenerated Electron Transport in ZnO Photoanodes for High-Efficiency Dye-Sensitized Solar Cells
}

\author{
Feng Xu, ${ }^{* \dagger}$ Jing Chen, ${ }^{\dagger}$ Xing Wu, ${ }^{\dagger}$ Yi Zhang, ${ }^{\dagger}$ Yuxi Wang, ${ }^{\dagger}$ Jun Sun, ${ }^{\dagger}$ Hengchang Bi, ${ }^{\dagger}$ Wei Lei, ${ }^{\ddagger}$ Yaru Ni, ${ }^{\S}$
} and Litao Sun* ${ }^{* \dagger}$

${ }^{\dagger}$ SEU-FEI Nano-Pico Center, Key Laboratory of MEMS of Ministry of Education, and ${ }^{\ddagger}$ Jiangsu Information Display Engineering Research Center, School of Electronic Science and Engineering, Southeast University, Nanjing 210096, China

${ }^{\S}$ State Key Laboratory of Materials-Oriented Chemical Engineering, Nanjing University of Technology, Nanjing 210009, China

Supporting Information

ABSTRACT: Graphene and $\mathrm{ZnO}$ as two star materials were united to constitute the photoanode of dye-sensitized solar cells (DSSCs). Highly electronically conductive graphene scaffolds incorporated into $\mathrm{ZnO}$ hierarchically structured nanoparticle (HSN) photoanodes could simultaneously capture and transport photogenerated electrons injected into $\mathrm{ZnO}$ by excited dyes. This strategy was beneficial for electrons to fluently transfer to the collection electrode due to the decreased internal resistance and electron recombination loss. On the basis of these advantages, the DSSC incorporating 1.2
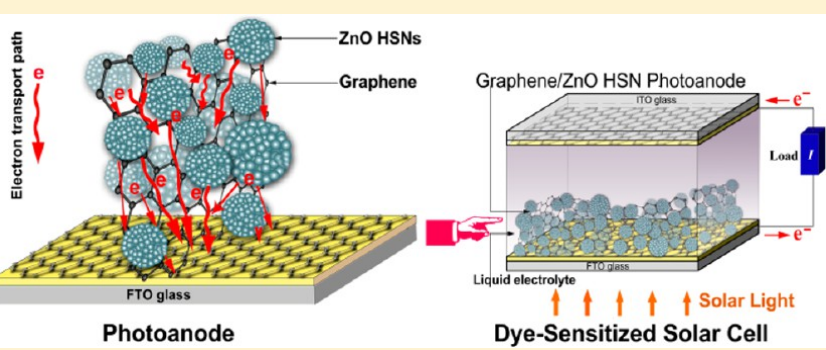
wt $\%$ graphene into the $\mathrm{ZnO}$ photoanode with $3 \mu \mathrm{m}$ in thickness exhibited a high short-circuit photocurrent density $\left(J_{\mathrm{sc}}\right)$ of 10.89 $\mathrm{mA} / \mathrm{cm}^{2}$ and a power conversion efficiency (PCE) of $3.19 \%$, which were increased by $43.48 \%$ and $38.09 \%$, respectively, compared with those of the DSSC without graphene. It was found that the incorporated graphene could markedly prolong electron lifetime $\left(\tau_{\text {eff }}\right)$ and effective diffusion length $\left(L_{\mathrm{n}}\right)$, which allowed the utilization of thicker photoanodes that could afford enhanced surface area for higher dye loading and light harvesting. Thus, an impressively high PCE of $5.86 \%$ was achieved for the DSSC composed of 9- $\mu$ m-thick $\mathrm{ZnO}$ photoanode, which could be the highest PCE compared with previous reports with the same thick photoanodes. These results demonstrate potential application of graphene for improving the performance of DSSCs.

\section{INTRODUCTION}

As a photovoltaic device, the dye-sensitized solar cell (DSSC) has recently emerged as a cost-effective alternative to conventional silicon photovoltaic devices at a very competitive cost. ${ }^{1}$ In $\mathrm{ZnO}$-based DSSCs, $\mathrm{ZnO}$ nanoparticle photoanodes with a high surface area have been extensively studied. ${ }^{2-9}$ Further enhancement in power conversion efficiency (PCE) by arbitrarily increasing the thickness of the photoanode to obtain higher dye loading and light harvesting has been limited by serious energy loss due to recombination between injected electrons and either the oxidized dye molecules or the electronaccepting species in the electrolyte during the electron transfer process across the $\mathrm{ZnO}$ nanoparticle network. ${ }^{10-12}$ Therefore, the utilization of $1 \mathrm{D}^{13-18}$ and $2 \mathrm{D}^{19-21} \mathrm{ZnO}$ nanostructure arrays as the photoanodes is expected to significantly extend the effective electron diffusion length $\left(L_{\mathrm{n}}\right)$ by providing a direct conduction pathway for rapid transport of photogenerated electrons to the collection electrode, which would diminish the possibility of electron recombination as in the nanoparticle network. However, the insufficient surface area of these simple $1 \mathrm{D}$ and $2 \mathrm{D} \mathrm{ZnO}$ nanostructure arrays sacrifices the dye loading and hence limits the further increase in PCE. In this regard, composite $\mathrm{ZnO}$ nanostructures combining multidimensional and hierarchical configurations (e.g., nanopartilces/nanorod arrays, $^{22,23}$ nanowires/nanosheet arrays, ${ }^{24,25}$ nanoforest ${ }^{26}$ ) seem to be desirable due to their increased surface area and reduced electron recombination. Even so, from the viewpoint of the large surface area, facile manufacture, and high PCE, the photoanodes based on $\mathrm{ZnO}$ nanoparticles with hierarchical structures are still attractive. ${ }^{2}$ Therefore, if we can commendably deal with serious electron recombination in nanoparticulate photoanodes by introducing charge carriers to direct electron transport toward the collection electrode, the improved cell performance with a considerably high PCE could be achieved. ${ }^{27}$

In this work, we incorporated the $2 \mathrm{D}$ graphene scaffolds with high electron mobility ${ }^{28}$ into $\mathrm{ZnO}$ hierarchically structured nanoparticle (HSN) photoanodes to act as charge carriers (as shown in Scheme 1). The interconnected graphene scaffolds serve as the "tentacle" to capture the injected electrons and as the "speedway" to enhance the electron transport rate for suppressing the electron recombination. To the best of our knowledge, there have been no reports on the enhancement of DSSCs by incorporating graphene into the matrix of $\mathrm{ZnO}$ photoanodes, other than simple surface modification and acting as collecting electrodes. Moreover, this strategy allows the

Received: December 16, 2012

Revised: March 24, 2013

Published: April 2, 2013 
Scheme 1. Schematic Diagram of the Graphene/ZnO HSN Composite Photoanode and Possible Electron Transport Path within the Structure

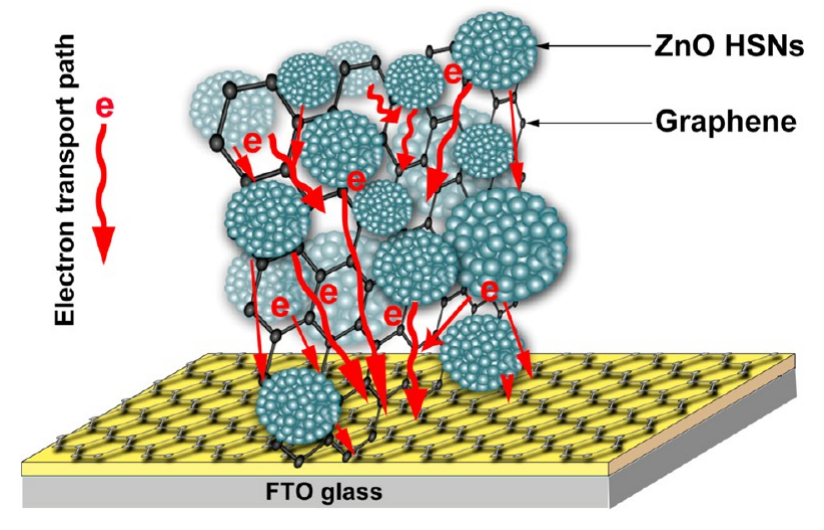

utilization of thicker photoanodes due to longer electron lifetime and longer electron effective diffusion length, resulting in larger surface area for higher dye loading and light harvesting. It was expected that the DSSCs using the graphene/ $\mathrm{ZnO} \mathrm{HSN}$ composite photoanodes with graphene scaffolds could yield an impressively high PCE compared with the ones using the photoanodes with $\mathrm{ZnO}$ nanoparticles alone.

\section{EXPERIMENTAL SECTION}

2.1. Synthesis of Graphene Oxide (Precursor to Graphene) and ZnO HSNs. Graphene oxide (GO) was prepared by chemically exfoliating expandable graphite $(E G)^{29}$ based on a modified Hummers method by us. ${ }^{30} \mathrm{ZnO} \mathrm{HSNs}$ were synthesized by the solvothermal process of zinc salt in polyol medium, similar to the method reported by D. Jezequel et al. $^{31}$ Detailed synthesis procedures can also be found in Supporting Information.

2.2. Preparation of Graphene/ZnO HSN Composite Photoanode. Graphene/ZnO HSN composite photoanodes were obtained by in situ reducing $\mathrm{GO}$ incorporated into $\mathrm{ZnO}$ HSN films. To prepare GO/ZnO composite electrodes, $6 \mathrm{~g}$ of PVA (MW 22 000) was added to $14 \mathrm{~mL}$ of boiled DW with powerful stirring, forming a highly viscous liquid that was further diluted in the mixed solvent $(18 \mathrm{~mL} \mathrm{DW}$ and $25 \mathrm{~mL}$ ethanol) at above $70{ }^{\circ} \mathrm{C}$. Then, $1.62 \mathrm{~g}$ of as-synthesized $\mathrm{ZnO}$ HSNs was added in batches to make the suspension of $\mathrm{ZnO}$. After this, $2.5 \mathrm{~mL}$ of $\mathrm{GO}$ aqueous solution with a certain concentration $(1-10 \mathrm{mg} / \mathrm{mL})$ was added into the suspension that was kept at continuous stirring for $2 \mathrm{~h}$ to enable good GO dispersion in the suspension. Subsequently, GO/ZnO composite suspension was cooled to room temperature and used to prepare the photoanode films by the doctor-blade technique on graphene/fluorine-doped tin oxide (FTO, $15 \Omega$ / $\square$ ) glass substrates, and the photoanode thickness could be modulated by controlling doctor-blade film-preparation times. The graphene/FTO electrode was prepared by a filtrationtransfer-reduction method ${ }^{32}$ that was initially developed for fabricating transparent, conductive CNT films. The preparation procedure of the graphene/ITO electrode can be schematically described as Scheme S1 in Supporting Information. The asprepared photoanodes were placed in vacuum at $120^{\circ} \mathrm{C}$ for $5 \mathrm{~h}$ to evaporate water and ethanol. Afterward, the electrodes were annealed at $450{ }^{\circ} \mathrm{C}$ under nitrogen gas flow for $5 \mathrm{~h}$, and the GO was reduced to graphene totally. Lastly, the electrodes were calcined at $500{ }^{\circ} \mathrm{C}$ for $3 \mathrm{~h}$. It is worth noting that the temperature increase or decrease must be controlled at very slow rate during the annealing and calcining processes of photoanodes. Pure ZnO HSN photoanodes were also prepared for comparison by doctor-blade technique on the graphene/ FTO substrates.

2.3. Assembly and Testing of DSSCs. The fabrication of DSSCs was performed as follows: Dying of the graphene/ $\mathrm{ZnO}$ composite photoanodes was performed in cis-bis(isothiocyanato) bis $\left(2,2^{\prime}\right.$-bipyridyl- $4,4^{\prime}$ - dicarboxylato)ruthenium(II)bis-tetrabutylammonium (N719, Solaronix) dye ethanolic solution $(0.3 \mathrm{mM})$ at $60^{\circ} \mathrm{C}$ for $1 \mathrm{~h}$. The photoanodes were then rinsed with ethanol to remove excessive dye molecules that were not directly adsorbed on $\mathrm{ZnO}$ and dried in air at room temperature. The sensitized photoanodes were sandwiched together with graphene/ITO counter electrodes separated by hot melt spacers $(60 \mu \mathrm{m}$ thick, Surlyn). The graphene/ITO electrodes were prepared by the same filtration-transfer-reduction method. ${ }^{32}$ The internal space of the two electrodes was filled with a liquid electrolyte composed of $0.05 \mathrm{M} \mathrm{I}_{2}, 0.5 \mathrm{M} \mathrm{LiI}, 0.5 \mathrm{M}$ 4-tert-butylpyridine, and $0.6 \mathrm{M}$ methylhexylimidazolium iodide in acetonitrile by capillary action. The photocurrent-photovoltage $(I-V)$ characteristics of the cell were measured with a Keithley model 2420 digital source meter and a Newport model $94022 \mathrm{~A}$ solar simulator system (equipped with a $150 \mathrm{~W}$ xenon arc lamp, Oriel) at one sun (AM 1.5G, $100 \mathrm{~mW} / \mathrm{cm}^{2}$ ), which was calibrated with a $\mathrm{Si}$ reference solar cell (Model $91150 \mathrm{~V}$, Oriel). The active cell area was typically $\sim 0.25 \mathrm{~cm}^{2}$ (defined by a lightproof black mask). The electrochemical impedance spectroscopy (EIS) measurements were performed using an electrochemical workstation (CHI-660D, Shanghai Chenhua Instruments, China) under illumination of one sun (AM 1.5G, $100 \mathrm{~mW} / \mathrm{cm}^{2}$ ) in the frequency range of $0.01 \mathrm{~Hz}$ to $1000 \mathrm{kHz}$. The applied bias voltage and ac amplitude were set at open-circuit photovoltage $\left(V_{\mathrm{oc}}\right)$ of the DSSCs and $10 \mathrm{mV}$ between the counter electrode and the working electrode (photoanode), respectively.

2.4. Characterization. The surface morphology and phase identification of the samples were investigated by a scanning electron microscope (SEM, JSM-5900, JEOL, Japan) operated at an acceleration voltage of $15 \mathrm{kV}$ and a powder X-ray diffractometer (XRD, ARL XTRA, Thermo Electron Co., USA) with $\mathrm{Cu} \mathrm{K} \alpha_{\mathrm{B}}$ radiation at a scan speed of $5^{\circ} / \mathrm{min}$ in the $2 \theta$ range between $5^{\circ}$ and $55^{\circ}$. The tube voltage and the tube current were $45 \mathrm{kV}$ and $35 \mathrm{~mA}$, respectively. Further structural analysis of the samples was carried out using a Cs-corrected high-resolution transmission electron microscope (HRTEM, Titan 80-300, FEI, U.S.A.) with an information limit of $80 \mathrm{pm}$ operated at an acceleration voltage of $300 \mathrm{kV}$. The TEM was equipped with a multiscan charge-coupled device (CCD) camera system (Model 894, Gatan, USA) to record the HRTEM images and selected area electron diffraction (SAED) patterns. The amount of dye loading was determined by deadsorbing the dye within the photoanode with $0.1 \mathrm{M} \mathrm{NaOH}$ solution and measuring the optical absorbance of dye solutions with a Shimadzu UV-3101PC spectrophotometer.

\section{RESULTS AND DISCUSSION}

GO was prepared by chemically exfoliating expandable graphite (EG) based on a modified Hummers method. Figure 1 shows the TEM image of free-standing GO nanosheets. The corrugated and scrolled sheets resemble crumpled silk veil waves, indicating their high flexility. Furthermore, the XRD pattern of GO in Figure 2a has a peak centered at $2 \theta=11.7^{\circ}$, 


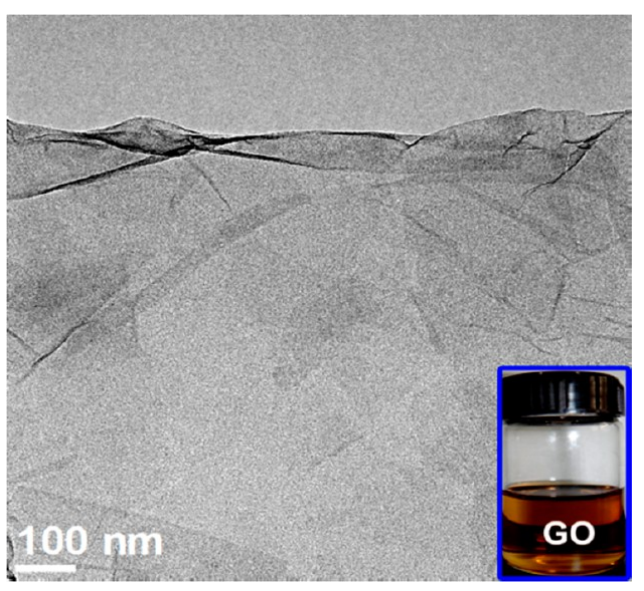

Figure 1. TEM image of as-prepared GO by chemically exfoliating expandable graphite.
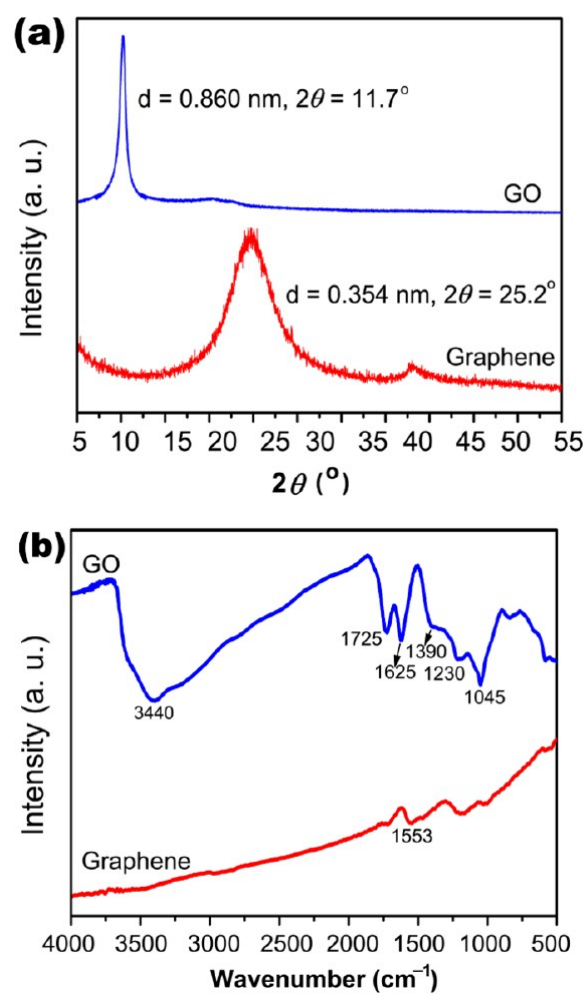

Figure 2. (a) XRD patterns and (b) FT-IR spectra of the pristine GO and the graphene separated from the reduced GO/ZnO HSN composite photoanodes ( $\sim 1.2 \mathrm{wt} \%$ graphene loading).

corresponding to a $d$-spacing of $8.60 \AA \AA^{33}$ which reflects intercalation of oxygen-containing functional groups into the pristine EG. All these confirm that the EG was exfoliated into small GO thin pieces by the strong chemical oxidation process. $^{34}$

GO incorporated into $\mathrm{ZnO}$ HSN photoanodes was in situ reduced to graphene by combining chemical reducing and annealing (see Experimental Section 2.2). To corroborate the validity and perfectibility of in situ reduction of GO in the composite photoanodes, the reduced composited photoanodes $(\sim 1.2$ wt \% graphene loading) were first immersed into diluted $\mathrm{HCl}$ solution for dissolving $\mathrm{ZnO}$ and then the reduced $\mathrm{GO}$ that is indissolvable was separated by centrifugation for further characterization. Figure $2 \mathrm{a}$ compares the XRD patterns of the pristine GO and reduced GO samples. After reducing GO, the basal spacing decreased from $8.60 \AA$ of the pristine GO to 3.54 $\AA$ of the reduced samples, indicating the removal of oxygenated groups and hence the formation of graphene. FT-IR spectra in Figure $2 \mathrm{~b}$ further validated the conversion from $\mathrm{GO}$ to graphene. In FT-IR spectrum of GO, typical vibrations are the strong and broad $\mathrm{O}-\mathrm{H}$ stretching peak at $3440 \mathrm{~cm}^{-1}$, the $\mathrm{C}=\mathrm{O}$ stretching peak at $1725 \mathrm{~cm}^{-1}$, the $\mathrm{O}-\mathrm{H}$ deformation peak at $1390 \mathrm{~cm}^{-1}$, the $\mathrm{C}-\mathrm{OH}$ stretching peak at $1230 \mathrm{~cm}^{-1}$, and the $\mathrm{C}-\mathrm{O}$ stretching peak at $1045 \mathrm{~cm}^{-1}$, respectively. ${ }^{35,36}$ The peak at around $1625 \mathrm{~cm}^{-1}$ due to the $\mathrm{O}-\mathrm{H}$ bending vibration, epoxide groups, and skeletal ring vibration are also observed, while in the spectrum of graphene, the $\mathrm{O}-\mathrm{H}, \mathrm{C}-\mathrm{O}$, and $\mathrm{C}=\mathrm{O}$ peaks are almost negligible, and a new peak at around $1553 \mathrm{~cm}^{-1}$ appears, which may be attributed to the skeletal vibration of the graphene sheets. All these characterizations imply the feasibility of in situ reduction of GO in the composite photoanodes.

Figure 3 shows a series of SEM images of $\mathrm{ZnO}$ HSN photoanode and graphene/ZnO HSN composite photoanode ( $\sim 1.2$ wt $\%$ graphene loading), respectively. Surface of $\mathrm{ZnO}$ HSN photoanode is porous and the pore size is uniform, as displayed in Figure 3a and c, while incorporating graphene into the $\mathrm{ZnO} H S N$ photoanode resulted in more and larger (even in the micrometer scale) pores and obvious surface asperity, as shown in Figure $3 \mathrm{~b}$ and $\mathrm{d}$. This phenomenon also happened in the case of $\mathrm{TiO}_{2} /$ graphene photoanodes. ${ }^{37,38}$ The pores could result from the release of $\mathrm{H}_{2} \mathrm{O}$ and $\mathrm{N}_{2} \mathrm{H}_{4}$ during the reduction and annealing of GO-incorporated $\mathrm{ZnO} \mathrm{HSN}$ photoanodes. The highly porous graphene/ $\mathrm{ZnO} \mathrm{HSN}$ composite photoanode is expected to have a higher surface area due to the increase in porosity compared with the $\mathrm{ZnO} \mathrm{HSN}$ photoanode. In addition, one can see from the cross-section SEM images (Figure $3 \mathrm{e}$ and $\mathrm{f}$ ) that both photoanode films possess nearly the same thickness $(3 \mu \mathrm{m})$, and are tightly adhered to FTO glass substrates. Note that, after reducing GO incorporated into $\mathrm{ZnO}$ HSN photoanodes by combining chemical reduction and annealing, the characteristic morphology of polycrystalline $\mathrm{ZnO}$ HSNs comprising smaller nanoscale particles was not impaired (see the inset in Figure 3d), which is also consistent with the TEM observation shown in Figure 4a. Further, HRTEM results provide direct evidence of the formation of graphene $/ \mathrm{ZnO}$ HSN composite structures, and graphene nanosheets have been successfully loaded onto $\mathrm{ZnO}$ HSNs (Figure 4b). While on the surface of $\mathrm{ZnO} \mathrm{HSNs}$ without incorporating graphene, no graphene nanosheets were found, as revealed by Figure $4 \mathrm{c}$.

The DSSC with the graphene/ZnO HSN composite photoanode ( $\sim 1.2$ wt $\%$ graphene loading) was assembled, and the configuration of the DSSC resembles the schematic diagram illustrated in Scheme 2. For comparison, the control experiment was also performed using the DSSC constructed by the $\mathrm{ZnO} \mathrm{HSN}$ photoanode. Figure 5 shows the compared photocurrent-voltage $(J-V)$ characteristics of both DSSCs under a simulated illumination with a light intensity of 100 $\mathrm{mW} / \mathrm{cm}^{2}$ (AM 1.5). The short-circuit current density $\left(J_{\mathrm{sc}}\right)$, the open-circuit voltage $\left(V_{\mathrm{oc}}\right)$, the fill factor $(F F)$, the maximum current output $\left(J_{\max }\right)$, the maximum voltage output $\left(V_{\max }\right)$, and the power conversion efficiency (PCE) derived from the $J-V$ curves for both DSSCs are summarized in Table 1 . It can be seen from Figure 5 and Table 1 that the $J_{\mathrm{sc}}\left(10.89 \mathrm{~mA} / \mathrm{cm}^{2}\right)$ for the DSSC constructed using the graphene/ $\mathrm{ZnO} \mathrm{HSN}$ composite photoanode show an obvious improvement of $43.48 \%$ over $J_{\text {sc }}\left(7.59 \mathrm{~mA} / \mathrm{cm}^{2}\right)$ of the DSSC constructed using 

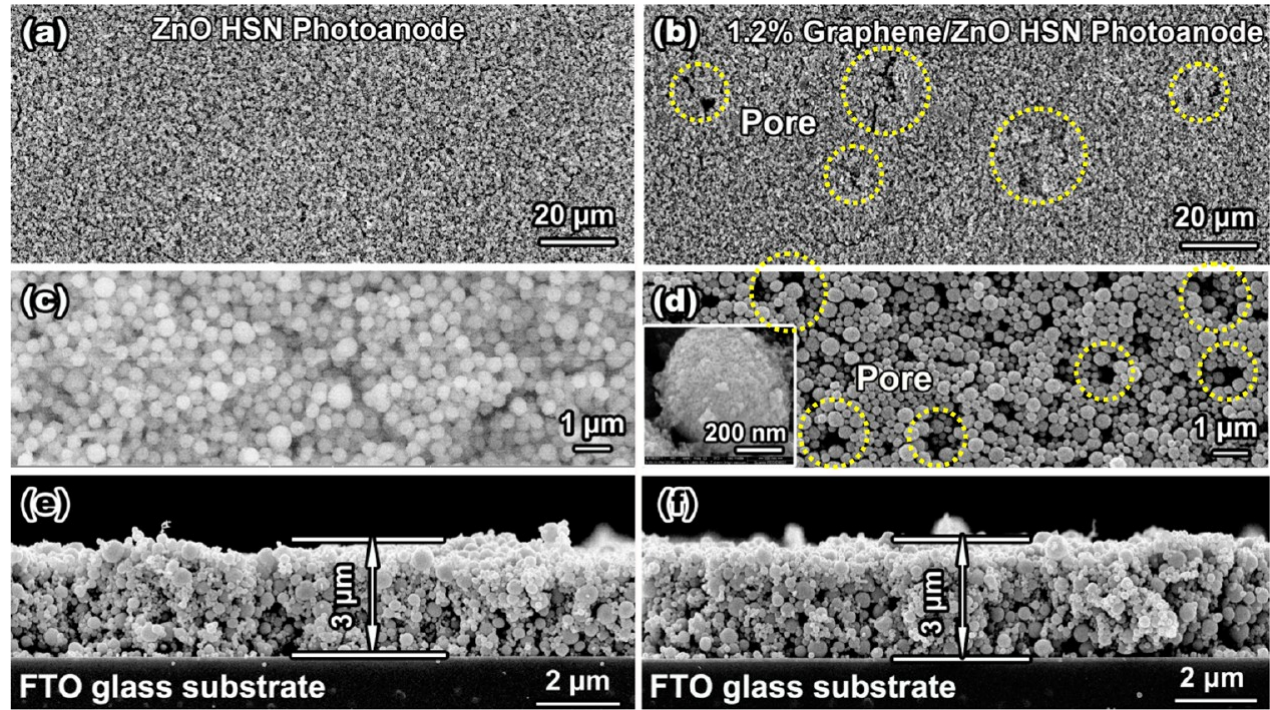

Figure 3. Plan-view SEM images of $(\mathrm{a}, \mathrm{c}) \mathrm{ZnO}$ HSN photoanode and $(\mathrm{b}, \mathrm{d})$ graphene/ZnO HSN composite photoanode ( 1.2 wt \% graphene loading). Inset in panel $d$ is the magnified image of an individual $\mathrm{ZnO}$ HSN. (e) and (f) are the cross-section SEM images of ZnO HSN photoanode and graphene/ZnO HSN composite photoanode, respectively.
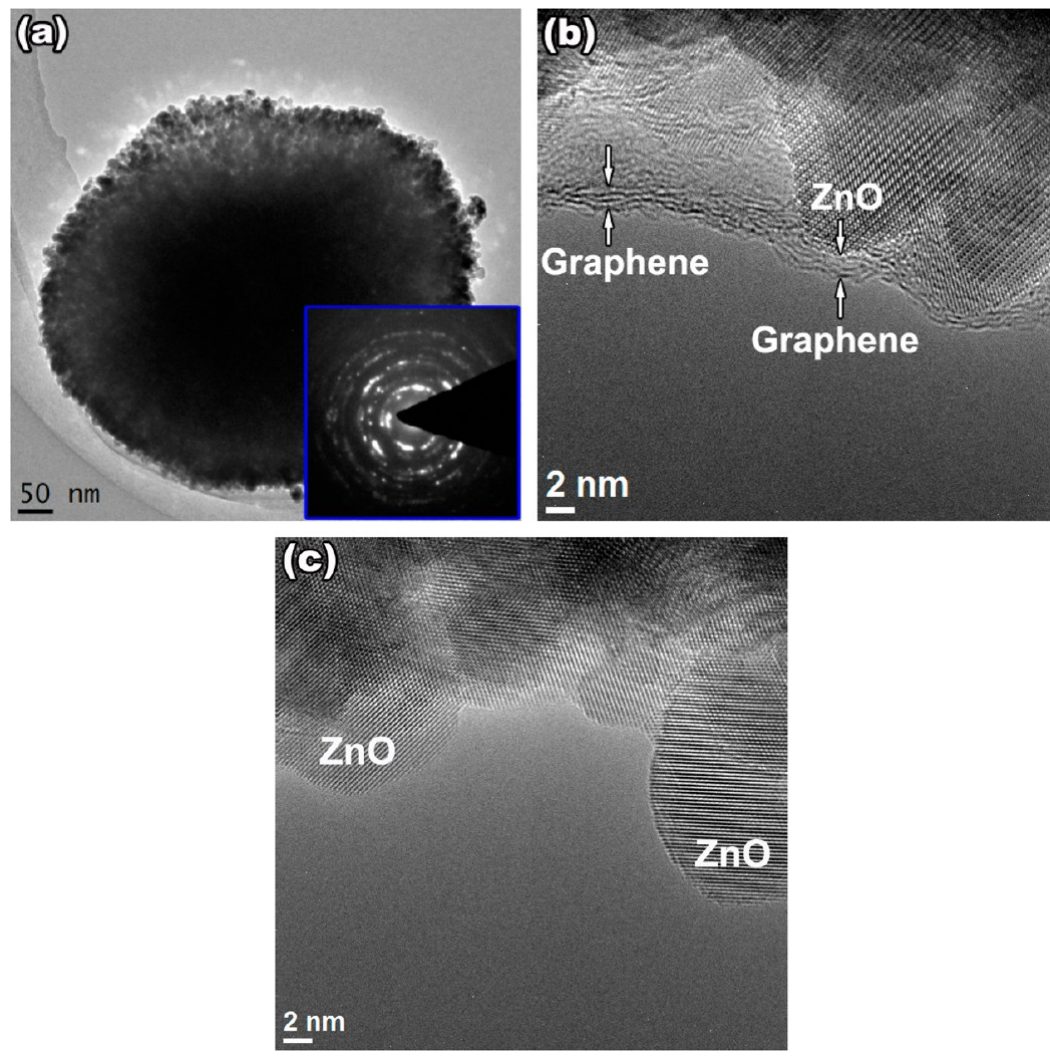

Figure 4. (a) TEM image, SAED pattern, and (b) HRTEM image of an individual ZnO HSN with graphene loading, and (c) HRTEM image of asprepared $\mathrm{ZnO} \mathrm{HSN}$ without graphene loading.

the $\mathrm{ZnO}$ HSN photoanode. A higher $J_{\text {sc }}$ would result in a higher PCE since the PCE is partly dependent on the $J_{s c}{ }^{5}$ Therefore, due to much improved $J_{s c}$ the graphene/ $\mathrm{ZnO}$ HSN composite photoanode based DSSC reached a total PCE of 3.19\%, which is nearly $38.09 \%$ higher than that of the ZnO HSN photoanode based DSSC $(2.31 \%)$. Besides, the FF increased a little from $42.1 \%$ to $47.6 \%$. However, there is no great difference in the $V_{\mathrm{oc}}$ for both the DSSCs. This phenomenon was also encountered in the case of $\mathrm{TiO}_{2} /$ graphene-based DSSCs. ${ }^{37,38}$ However, according to P. V. Kamat's work, ${ }^{39,40}$ the incorporation of CNTs into the $\mathrm{TiO}_{2}$ photoanode resulted in an obvious decrease in the $V_{\mathrm{oc}}$ as well as a great increase in the $J_{\mathrm{sc}}$. This was because the apparent Fermi level of CNTs-based photoanode decreased in comparison with that of a pristine photoanode without CNTs, and thus the $V_{\text {oc }}$ was sacrificed as a result. Herein, the graphene is a zero band material, and its calculated work function is a little more positive $(-4.42 \mathrm{eV}$ vs vacuum) than that of the CNTs. As a result, the apparent Fermi level of 
Scheme 2. Schematic Diagram of the DSSC Based on the Graphene-Incorporated Hierarchically Structured $\mathrm{ZnO}$ Nanoparticale Photoanode
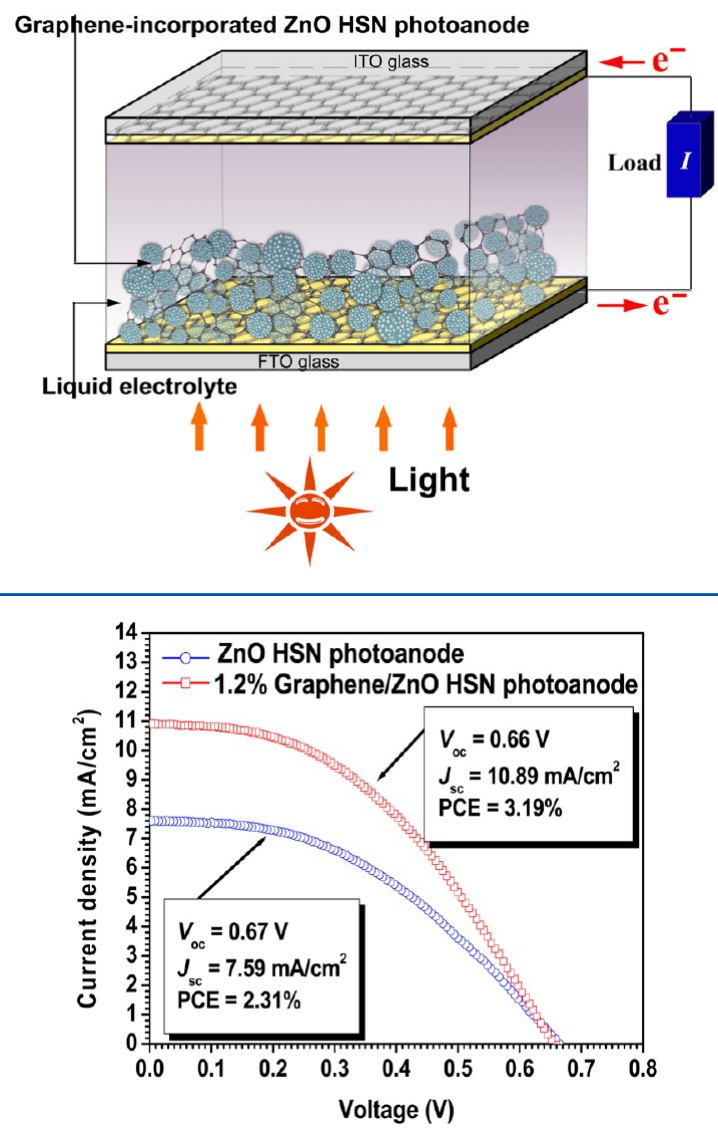

Figure 5. Current-voltage $(J-V)$ characteristics of the DSSCs constructed using the $\mathrm{ZnO} \mathrm{HSN}$ photoanode and graphene/ZnO HSN composite photoanode ( $\sim 1.2$ wt \% graphene loading) under a simulated illumination with a light intensity of $100 \mathrm{~mW} / \mathrm{cm}^{2}$ (AM $1.5)$.

Table 1. Photovoltaic Parameters of the DSSCs Based on the ZnO HSN Photoanode and Graphene/ZnO HSN ( 1.2 wt \% Graphene Loading), Respectively

\begin{tabular}{lccccc}
\multicolumn{1}{c}{ photoanode } & $\begin{array}{c}\text { thickness } \\
(\mu \mathrm{m})\end{array}$ & $\begin{array}{c}V_{\mathrm{oc}} \\
(\mathrm{V})\end{array}$ & $\begin{array}{c}J_{\mathrm{sc}} \\
\left(\mathrm{mA} / \mathrm{cm}^{2}\right)\end{array}$ & $F F(\%)$ & $\begin{array}{c}\mathrm{PCE} \\
(\%)\end{array}$ \\
\hline ZnO HSN & 3 & 0.67 & 7.6 & 42.10 & 2.31 \\
$\begin{array}{l}\text { Graphene/ZnO HSN } \\
(\sim 1.2 \mathrm{wt} \% \text { graphene } \\
\text { loading })\end{array}$ & 3 & 0.66 & 10.89 & 47.60 & 3.19 \\
\hline
\end{tabular}

the graphene-based photoanode might not be decreased, and thus the $V_{\text {oc }}$ was not affected greatly.

Due to the unconspicuous changes in the $V_{\text {oc }}$ and $F F$ for both the DSSCs, the increase in $J_{\mathrm{sc}}$ should be mainly responsible for the enhancement in the PCE of the DSSC with graphene/ $\mathrm{ZnO}$ HSN composite photoanode. Generally, the increase in $J_{s c}$ is attributed to several dominant factors including the utilization of photosensitizers with (i) higher extinction coefficient, (ii) the incorporation of photoanodes with larger surface area or functionalized microstructure for more light harvesting, and (iii) the control over recombination of photogenerated electrons. Here, the photosensitizer (N719 dye) adopted is the same for both DSSCs. Moreover, we estimated the amount of dye loading by contrasting the optical absorbance of solutions containing dyes desorbed from the photoanodes ( 3 $\mu \mathrm{m}$ in thickness) with that of dye solution with a known concentration (see Figure 6). Results show that, for the

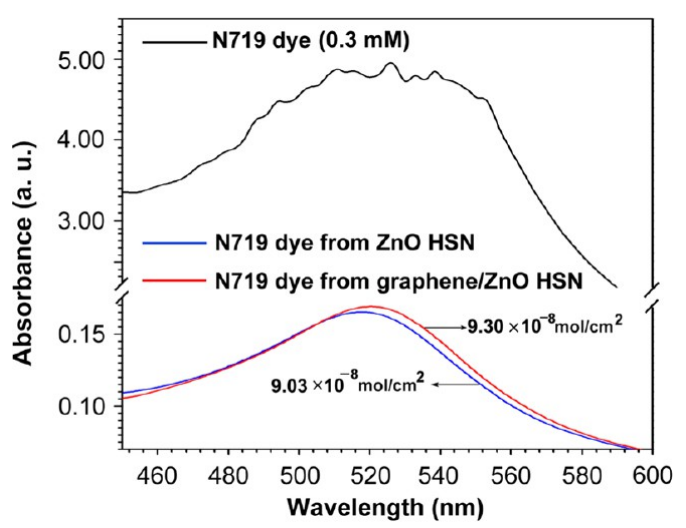

Figure 6. Optical absorbance of solutions containing dyes detached from the $\mathrm{ZnO} \mathrm{HSN}$ photoanode and graphene/ZnO HSN photoanode, respectively.

graphene $/ \mathrm{ZnO} \mathrm{HSN}$ photoanode, the value is $9.30 \times 10^{-8}$ $\mathrm{mol} / \mathrm{cm}^{2}$ that is increased by $3 \%$ in comparison with $9.03 \times$ $10^{-8} \mathrm{~mol} / \mathrm{cm}^{2}$ of $\mathrm{ZnO} \mathrm{HSN}$ photoanode. Obviously, only $3 \%$ increase in dye loading amount is incompatible with the $43.48 \%$ increase in the $J_{\mathrm{sc}}$. Thus, the reduced electron recombination should be mainly responsible for the $J_{s c}$ enhancement, which could profit from the incorporation of graphene for rapidly transporting the electrons within the photoanodes.

To corroborate the effect of graphene in transporting the electrons and restraining the back electron transfer, the electrochemical properties of both photoanodes were investigated by electrochemical impedance spectra (EIS) under illumination of one sun (AM 1.5G, $100 \mathrm{~mW} / \mathrm{cm}^{2}$ ) at an applied bias of $V_{\mathrm{oc}}$ as shown in Figure 7. In the Nyquist plots (Figure $7 a)$, there are two semicircles in high-frequency region and middle-frequency region, respectively. The one in the highfrequency region relates to the charge transfer resistance $\left(R_{\mathrm{ct}}\right)$ at the electrolyte/counter electrode interface, while the other in the middle frequency region corresponds to the charge transfer resistance $\left(R_{\mathrm{w}}\right)$ in the photoanode. ${ }^{41}$ The corresponding equivalent circuit of the device is insetted in Figure $7 \mathrm{a}$. Compared with the $\mathrm{ZnO} \mathrm{HSN}$ photoanode, the semicircle size in the middle frequency for the graphene/ $\mathrm{ZnO} \mathrm{HSN}$ photoanode (1.2 wt \% graphene loading) obviously decreases, implying acceleration of the electron transfer process due to lower $R_{\mathrm{w}}{ }^{41,42}$ This result is also supported by the corresponding Bode plots (Figure $7 \mathrm{~b}$ ). The phase shift of the characteristic frequency peak $(10-100 \mathrm{~Hz})$ is greatly reduced from $33^{\circ}$ for the DSSC with $\mathrm{ZnO} \mathrm{HSN}$ photoanode to $28^{\circ}$ for the DSSC with graphene/ $\mathrm{ZnO}$ HSN photoanode. Correspondingly, the position of the characteristic frequency peak is shifted to a lower frequency (from 23.5 to $10.7 \mathrm{~Hz}$ ). Any shift of the peak from high frequency to low frequency reveals a more rapid electron transport process due to longer electron lifetime $\left(\tau_{\text {eff }}\right)$, because the value $\left(f_{\text {mid }}\right)$ of the middle frequency is related to the inverse of $\tau_{\text {eff }}$ as follows: $\tau_{\text {eff }}=1 /\left(2 \pi f_{\text {mid }}\right){ }^{42}$ For the DSSC with the graphene/ $\mathrm{ZnO} \mathrm{HSN}$ composite photoanode, longer electron lifetime ( $93.4 \mathrm{~ms}$ ) is obtained compared with $42.5 \mathrm{~ms}$ for the DSSC with the ZnO HSN photoanode. Therefore, the Nyquist plots and Bode phase plots show that incorporating graphene into the $\mathrm{ZnO} \mathrm{HSN}$ photoanode greatly improved the 

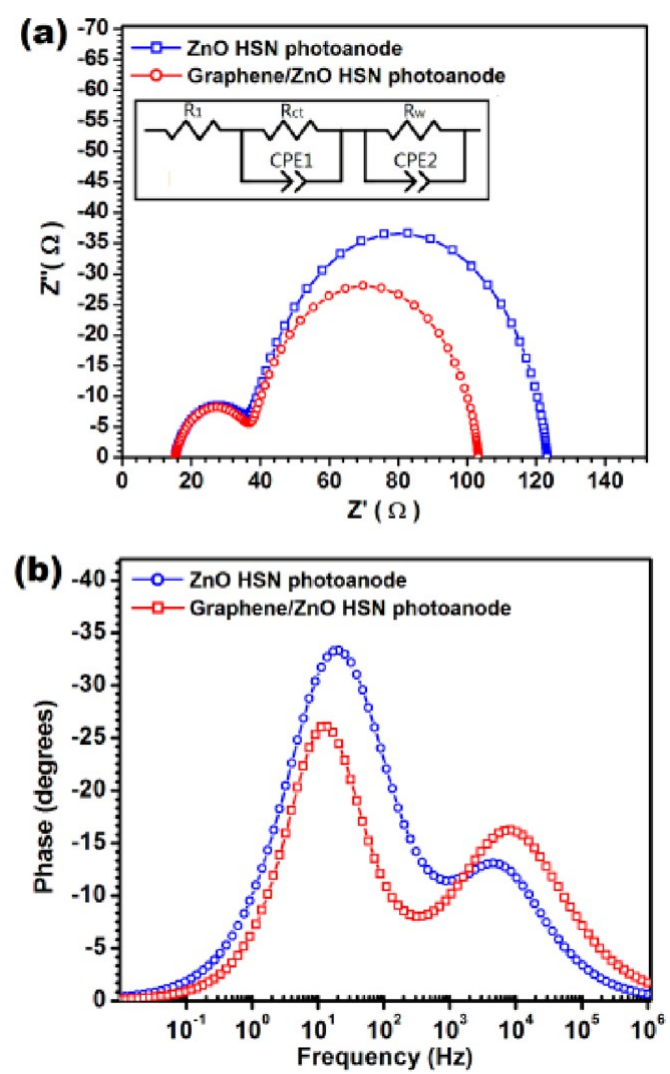

Figure 7. (a) Nyquist and (b) Bode plots of the electrochemical impedance spectra of the $\mathrm{ZnO} \mathrm{HSN}$ photoanode and graphene/ $\mathrm{ZnO}$ HSN photoanode. Inset in (a) is the equivalent circuit of the device. The spectra were measured under the illumination of one sun at opencircuit potential.

electrochemical activity due to the prolonged $\tau_{\text {eff }}$ In other words, the electrons with longer $\tau_{\text {eff }}$ can obtain longer effective diffusion length $\left(L_{\mathrm{n}}\right)$ and more easily escape the electron recombination. $L_{\mathrm{n}}$ reflects the competition between electron transport and recombination in DSSCs, ${ }^{43}$ and it can be derived from the equations, $L_{\mathrm{n}}{ }^{2}=D_{\text {eff }} \times \tau$ and $D_{\text {eff }}=\left(R_{\mathrm{w}} / R_{\mathrm{k}}\right) L^{2} k_{\text {eff }} 44,45$ where $R_{\mathrm{k}}, L$, and $k_{\text {eff }}$ represent the resistance of charge transfer related to the recombination, the thickness of the photoanode, and the effective constant rate for recombination, respectively. These values can be estimated from the central arc of Nyquist and Bode plots according to the suggestion by J. L. Song. ${ }^{46}$ The calculated $R_{\mathrm{w}} / R_{\mathrm{k}}, k_{\text {eff, }} D_{\text {eff }}$, and the resultant $L_{\mathrm{n}}$ are summarized in Table 2. Obviously, the graphene/ $\mathrm{ZnO}$ HSN photoanode has a longer $L_{\mathrm{n}}(14.43 \mu \mathrm{m})$ compared with $8.37 \mu \mathrm{m}$ of the $\mathrm{ZnO}$ HSN photoanode, implying that the former has lower electron recombination.

According to the above-mentioned discussions, we conclude that the incorporation of graphene into the $\mathrm{ZnO} \mathrm{HSN}$ photoanode can enable the DSSC devices operate more efficiently. Scheme 3 shows the schematic energy diagram of operation principle of the DSSCs with the $\mathrm{ZnO} \mathrm{HSN}$ photoanode and graphene/ZnO HSN photoanode, respectively. In the photoanode of the latter, as graphene has a work function $(-4.42 \mathrm{eV}$ vs vacuum) similar to that of FTO $(-4.4$ $\mathrm{eV}$ vs vacuum $),{ }^{47}$ it acts more like many extended "tentacle" penetrating into $\mathrm{ZnO} \mathrm{HSN}$ matrix for rapidly capturing, transporting, and collecting electrons injected into $\mathrm{ZnO}$ before being recombined, and hence the adverse electron transfers (recombination and back transfer) are suppressed in a way, while in the photoanode of the former, photogenerated electrons have to transfer through the $\mathrm{ZnO} \mathrm{HSN}$ film which is several or even dozens of micrometers thick before reaching the FTO collection electrode. Therefore, the recombination chance for electrons and holes is inevitably increased.

Since the incorporation of graphene into the $\mathrm{ZnO} \mathrm{HSN}$ photoanode can enhance the PCE of the DSSCs, the graphene loading content should be a paramount factor that directly decides the cell performance. The current-voltage $(J-V)$ characteristics and photovoltaic parameters of the DSSCs based on the graphene/ $\mathrm{ZnO} \mathrm{HSN}$ composite photoanodes with different graphene loading contents are displayed in Figure 8 and Table 3. The results show that the cell PCE would not be enhanced at all times with the increase of graphene loading content, and $1.2 \mathrm{wt} \%$ graphene loading is optimal for the 3$\mu \mathrm{m}$-thick photoanode. The superfluous graphene increased the probability of contact with the electrolyte and became a kind of recombination center instead of providing an electron pathway. ${ }^{37}$ At the same time, the incorporation of excessive graphene led to the cracks of photoanodes that resulted from the excess release of $\mathrm{H}_{2} \mathrm{O}$ and $\mathrm{N}_{2} \mathrm{H}_{4}$ during the reduction of GO. All of these make the short circuit happen easily, causing the decrease of the cell PCE. For instance, the DSSC with even 4.0 wt \% graphene loading cannot work at all due to the serious cracks of the photoanodes (see Supporting Information Figure S1).

Based on the EIS analysis, the incorporation of graphene into $\mathrm{ZnO} \mathrm{HSN}$ photoanodes can prolong the photogenerated electron lifetime $(\tau)$ and hence obtain longer effective diffusion length $\left(L_{\mathrm{n}}\right)$ and more easily escape from the recombination. This strategy accommodates the utilization of thick photoanodes that could afford enhanced surface area for higher dye loading and light harvesting. Figure 9 and Table 4 show the current-voltage $(J-V)$ characteristics and photovoltaic parameters of the DSSCs based on the graphene/ZnO HSN composite photoanodes with different photoanode thicknesses. With increasing the photoanode thickness from 3 to $9 \mu \mathrm{m}$, the short-circuit current density correspondingly rose. Apparently, the PCE also exhibited the similar change trend. The highest PCE of $5.86 \%$ was obtained for the DSSC composed of $9-\mu \mathrm{m}$ thick graphene/ $\mathrm{ZnO} \mathrm{HSN}$ composite photoanode with $1.2 \mathrm{wt}$ $\%$ graphene loading. This value could be the highest among the previous $\mathrm{ZnO} H S N$-based DSSCs with the parallel photoanode thickness, ${ }^{48,49}$ as listed in Table 5. Further increasing the photoanode thickness to $25 \mu \mathrm{m}$, the short-circuit current density descended promptly. This phenomenon indicates that the prolonged electron lifetime and effective diffusion length

Table 2. Parameters Derived from Nyquist and Bode plots of EIS of the ZnO HSN Photoanode and Graphene/ZnO HSN Photoanode

\begin{tabular}{lccccccc}
\hline \multicolumn{1}{c}{ photoanode } & $R_{\mathrm{w}}(\Omega)$ & $R_{\mathrm{k}} / R_{\mathrm{w}}$ & $k_{\text {eff }}\left(\mathrm{s}^{-1}\right)$ & $\tau(\mathrm{ms})$ & $\tau_{\text {eff }}(\mathrm{ms})$ & $D_{\text {eff }}\left(\mathrm{cm}^{2} \mathrm{~s}^{-1}\right)$ & $L_{\mathrm{n}}(\mu \mathrm{m})$ \\
\hline ZnO HSN & 86 & 7.8 & 23.5 & 42.5 & 6.8 & $1.65 \times 10^{-5}$ & 8.37 \\
Graphene/ZnO HSN $(\sim 1.2 \mathrm{wt} \%$ graphene loading $)$ & 65 & 23.2 & 10.7 & 93.4 & 14.9 & $2.23 \times 10^{-5}$ & 14.43
\end{tabular}


Scheme 3. Schematic Energy Diagram of Operation Principle of the DSSCs with ZnO HSN Photoanode and Graphene/ZnO HSN Photoanode, Respectively, Illustrating the Electron Injection from Excited Dye into ZnO and Transport of the Injected Electrons to the Collection Electrode

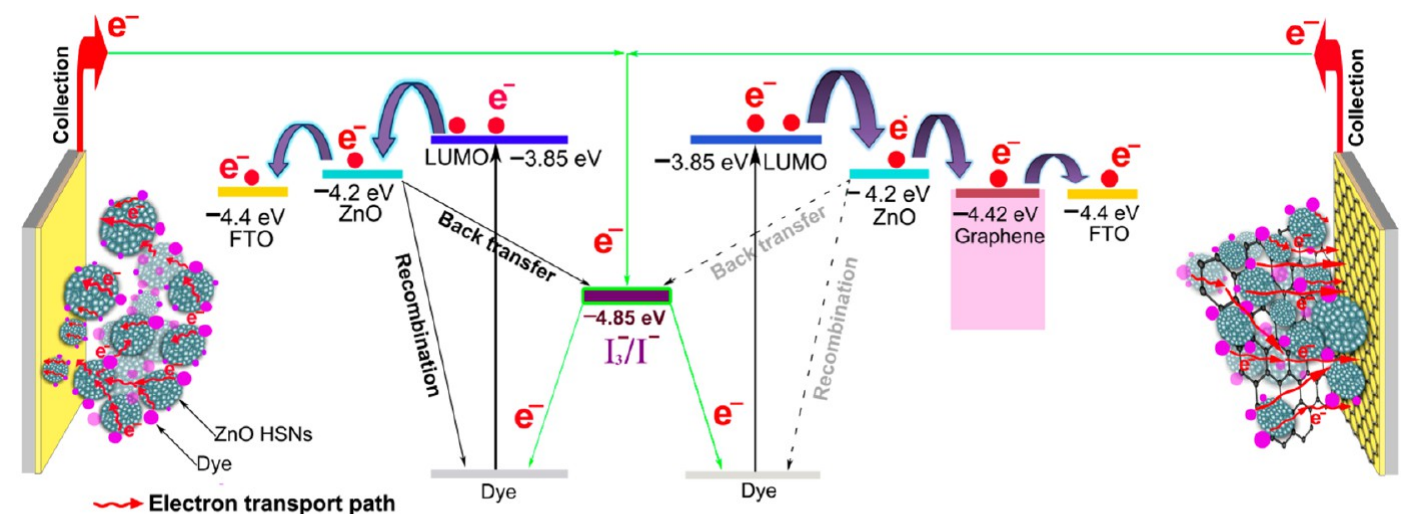

ZnO HSN Photoanode

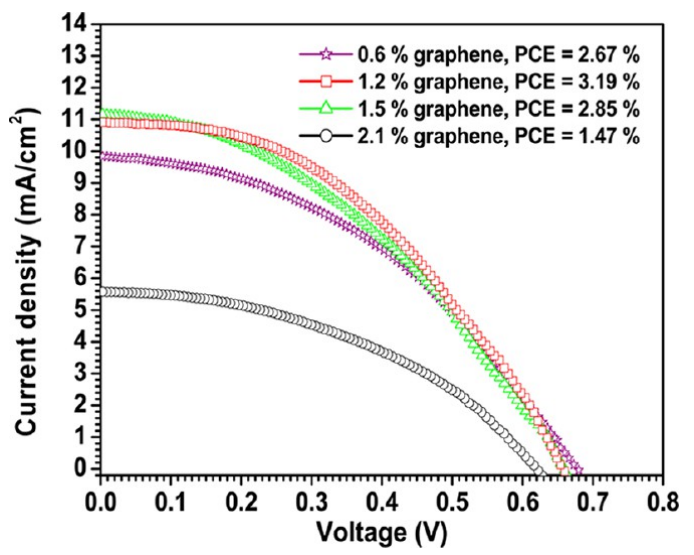

Figure 8. Current-voltage $(J-V)$ characteristics of the DSSCs constructed using the graphene/ZnO HSN composite photoanode (3 $\mu \mathrm{m}$ thick) with different graphene loading contents ( $0.6 \mathrm{wt} \%, 1.2$ wt \%, 2.1 wt \%, and 4.0 wt \%, respectively) under a simulated illumination with a light intensity of $100 \mathrm{~mW} / \mathrm{cm}^{2}$ (AM 1.5).

Table 3. Photovoltaic Parameters of the DSSCs Based on the Graphene/ZnO HSN Composite Photoanodes with Different Graphene Loading Contents

\begin{tabular}{|c|c|c|c|c|c|}
\hline $\begin{array}{l}\text { graphene } / \mathrm{ZnO} \\
\text { HSN composite } \\
\text { photoanode }\end{array}$ & $\begin{array}{l}\text { thickness } \\
\qquad(\mu \mathrm{m})\end{array}$ & $V_{\mathrm{oc}}(\mathrm{V})$ & $\underset{\left(\mathrm{mA} / \mathrm{cm}^{2}\right)}{J_{\mathrm{sc}}}$ & $F F(\%)$ & PCE (\%) \\
\hline $\begin{array}{l}0.6 \text { wt } \% \text { graphene } \\
\text { loading }\end{array}$ & 3 & 0.69 & 9.80 & 45.20 & 2.67 \\
\hline $\begin{array}{l}1.2 \mathrm{wt} \% \text { graphene } \\
\text { loading }\end{array}$ & 3 & 0.66 & 10.89 & 47.60 & 3.19 \\
\hline $\begin{array}{l}1.5 \text { wt } \% \text { graphene } \\
\text { loading }\end{array}$ & 3 & 0.68 & 11.09 & 38.44 & 2.85 \\
\hline $\begin{array}{l}2.1 \mathrm{wt} \% \text { graphene } \\
\text { loading }\end{array}$ & 3 & 0.64 & 5.55 & 39.16 & 1.47 \\
\hline $\begin{array}{l}4.0 \text { wt \% graphene } \\
\text { loading }\end{array}$ & 3 & N/A & N/A & $\mathrm{N} / \mathrm{A}$ & $\mathrm{N} / \mathrm{A}$ \\
\hline
\end{tabular}

have not counteracted the huge electron recombination loss during the electron transport to the collection electrode within the thicker photoanodes. Correspondingly, the total conversion efficiencies of the DSSCs suffering from the decreased photocurrent were inevitably decreased.
Graphene/ZnO HSN Photoanode

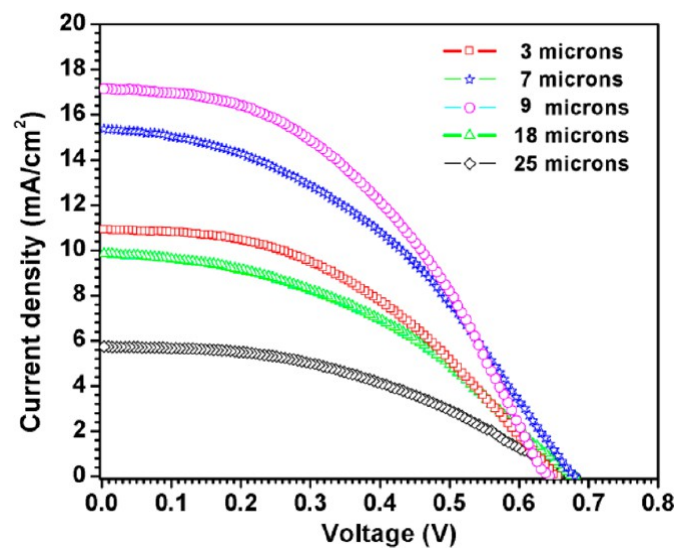

Figure 9. (a) Current-voltage $(J-V)$ characteristics of the DSSCs constructed using the graphene/ $\mathrm{ZnO}$ HSN composite photoanode (1.2 wt \% graphene loading) with different thickness ( $3 \mu \mathrm{m}, 7 \mu \mathrm{m}, 9$ $\mu \mathrm{m}, 18 \mu \mathrm{m}$, and $25 \mu \mathrm{m}$, respectively) under a simulated illumination with a light intensity of $100 \mathrm{~mW} / \mathrm{cm}^{2}$ (AM 1.5 ).

Table 4. Photovoltaic Parameters of the DSSCs Based on the Graphene/ZnO HSN Composite Photoanodes with Different Photoanode Thickness

\begin{tabular}{|c|c|c|c|c|c|}
\hline $\begin{array}{l}\text { graphene/ZnO HSN } \\
\text { composite photoanode }\end{array}$ & $\begin{array}{l}\text { thickness } \\
(\mu \mathrm{m})\end{array}$ & $\begin{array}{l}V_{\text {oc }} \\
(\mathrm{V})\end{array}$ & $\underset{\left(\mathrm{mA} / \mathrm{cm}^{2}\right)}{J_{\mathrm{sc}}}$ & $F F(\%)$ & $\begin{array}{l}\text { PCE } \\
(\%)\end{array}$ \\
\hline $\begin{array}{l}1.2 \text { wt } \% \text { graphene } \\
\text { loading }\end{array}$ & 3 & 0.66 & 10.89 & 47.60 & 3.19 \\
\hline $\begin{array}{l}1.2 \text { wt } \% \text { graphene } \\
\text { loading }\end{array}$ & 7 & 0.68 & 15.32 & 41.15 & 5.07 \\
\hline $\begin{array}{l}1.2 \text { wt \% graphene } \\
\text { loading }\end{array}$ & 9 & 0.67 & 17.11 & 42.03 & 5.86 \\
\hline $\begin{array}{l}1.2 \text { wt } \% \text { graphene } \\
\text { loading }\end{array}$ & 18 & 0.69 & 9.80 & 38.83 & 2.77 \\
\hline $\begin{array}{l}1.2 \text { wt \% graphene } \\
\text { loading }\end{array}$ & 25 & 0.69 & 5.72 & 36.21 & 1.58 \\
\hline
\end{tabular}

\section{CONCLUSIONS}

In conclusion, we reported for the first time the incorporation of graphene into the matrix of $\mathrm{ZnO} \mathrm{HSN}$ photoanodes of the DSSCs for improving photogenerated electron transport. It was found that incorporating graphene effectively decreased the internal resistance within the photoanodes and prolonged the 
Table 5. Comparison between Our Work and Previously Published Works

\begin{tabular}{llcc} 
reference & \multicolumn{1}{c}{ photoanode } & thickness $(\mu \mathrm{m})$ & PCE $(\%)$ \\
Our work & Graphene/ZnO HSN & 3 & 3.19 \\
48 & ZnO HSN & 3.5 & 2.25 \\
49 & Iodine-doped ZnO HSN & 8 & 4.5 \\
Our work & Graphene/ZnO HSN & 9 & 5.86 \\
5 & ZnO HSN & 10 & 3.51 \\
7 & ZnO HSN & 10 & 4.4 \\
8 & ZnO HSN & 27 & 5.34 \\
\hline
\end{tabular}

electron lifetime, which can reduce the electron recombination loss. Thus, the DSSCs with incorporating an optimal amount (1.2 wt \%) of graphene showed the markedly enhancement in PCE compared with the DSSCs without graphene. The results demonstrate potential application of graphene for enhancing the performance of nanoparticles-based DSSCs that can be produced on a large scale by a low-cost and high-efficiency rollto-roll process.

\section{ASSOCIATED CONTENT}

\section{S Supporting Information}

Experimental section of synthesizing graphene oxide and $\mathrm{ZnO}$ HSNs, schematic diagram for the preparation of graphene film electrodes, and some supplementary SEM images are provided. This information is available free of charge via the Internet at http://pubs.acs.org.

\section{AUTHOR INFORMATION}

\section{Corresponding Author}

*Phone: +86 25 83792632. Fax: +86 25 83792939. E-mail: fxu@seu.edu.cn (F. Xu); slt@seu.edu.cn (L.-T. Sun).

\section{Author Contributions}

F. X., J. C., and X. W. contributed equally to this work.

\section{Notes}

The authors declare no competing financial interest.

\section{ACKNOWLEDGMENTS}

Helpful discussions with Binjie Wang and Tao $\mathrm{Xu}$ are appreciated. This work was supported by the National Basic Research Program of China (973 Program, Grant Nos. 2011CB707601 and 2009CB623702), the National Natural Science Foundation of China (NSFC, Grant Nos. 21243011, 61106055, 61274114, 51071044, 51202028, and 61006011), the Fundamental Research Funds for the Central Universities, China Postdoctoral Science Foundation Funded Project (Grant Nos. 20100470066 and 201104501, 2012M520053), and Jiangsu Planned Projects for Postdoctoral Research Funds (Grant No. 0902003B).

\section{REFERENCES}

(1) Oregan, B.; Gratzel, M. A Low-Cost, High-Efficiency Solar Cell Based on Dye-Sensitized Colloidal $\mathrm{TiO}_{2}$ Films. Nature 1991, 353, 737-739.

(2) Saito, M.; Fujihara, S. Large Photocurrent Generation in DyeSensitized ZnO Solar Cells. Energy Environ. Sci. 2008, 1, 280-283.

(3) $\mathrm{Xu}$, F.; Sun, L. T. Solution-Derived $\mathrm{ZnO}$ Nanostructures for Photoanodes of Dye-Sensitized Solar Cells. Energy Environ. Sci. 2011, 4, 818-841.

(4) Keis, K.; Bauer, C.; Boschloo, G.; Hagfeldt, A.; Westermark, K.; Rensmo, H.; Siegbahn, H. Nanostructured $\mathrm{ZnO}$ Electrodes for Dye-
Sensitized Solar Cell Applications. J. Photochem. Photobiol. A 2002, $148,57-64$

(5) Chou, T. P.; Zhang, Q. F.; Fryxell, G. E.; Cao, G. Z. Hierarchically Structured $\mathrm{ZnO}$ Film for Dye-Sensitized Solar Cells with Enhanced Energy Conversion Efficiency. Adv. Mater. 2007, 19, $2588-2592$.

(6) Zhang, Q. F.; Chou, T. R.; Russo, B. S.; Jenekhe, A.; Cao, G. Z. Aggregation of $\mathrm{ZnO}$ Nanocrystallites for High Conversion Efficiency in Dye-Sensitized Solar Cells. Angew. Chem., Int. Ed. 2008, 47, 24022406.

(7) Zhang, Q. F.; Chou, T. P.; Russo, B.; Jenekhe, S. A.; Cao, G. Z. Polydisperse Aggregates of $\mathrm{ZnO}$ Nanocrystallites: A Method for Energy-Conversion-Efficiency Enhancement in Dye-Sensitized Solar Cells. Adv. Funct. Mater. 2008, 18, 1654-1660.

(8) Cheng, H. M.; Hsieh, W. F. High-Efficiency Metal-Free OrganicDye-Sensitized Solar Cells with Hierarchical $\mathrm{ZnO}$ Photoelectrode. Energy Environ. Sci. 2010, 3, 442-447.

(9) Yoshida, T.; Zhang, J. B.; Komatsu, D.; Sawatani, S.; Minoura, H.; Pauporte, T.; Lincot, D.; Oekermann, T.; Schlettwein, D.; Tada, H.; et al. Electrodeposition of Inorganic/Organic Hybrid Thin Films. Adv. Funct. Mater. 2009, 19, 17-43.

(10) Nissfolk, J.; Fredin, K.; Hagfeldt, A.; Boschloo, G. Recombination and Transport Processes in Dye-Sensitized Solar Cells Investigated under Working Conditions. J. Phys. Chem. B 2006, 110, 17715-17718.

(11) Gratzel, M. Solar Energy Conversion by Dye-Sensitized Photovoltaic Cells. Inorg. Chem. 2005, 44, 6841-6851.

(12) Gratzel, M. Conversion of Sunlight to Electric Power by Nanocrystalline Dye-Sensitized Solar Cells. J. Photochem. Photobiol. A 2004, 164, 3-14.

(13) Law, M.; Greene, L. E.; Johnson, J. C.; Saykally, R.; Yang, P. D. Nanowire Dye-Sensitized Solar Cells. Nat. Mater. 2005, 4, 455-459.

(14) Baxter, J. B.; Walker, A. M.; Ommering, K.; Aydil, E. S. Synthesis and Characterization of $\mathrm{ZnO}$ Nanowires and Their Integration into Dye-Sensitized Solar Cells. Nanotechnology 2006, 17, S304-S312.

(15) Xu, C. K.; Shin, P.; Cao, L. L.; Gao, D. Preferential Growth of Long $\mathrm{ZnO}$ Nanowire Array and Its Application in Dye-Sensitized Solar Cells. J. Phys. Chem. C 2010, 114, 125-129.

(16) Qiu, J. J.; Li, X. M.; Zhuge, F. W.; Gan, X. Y.; Gao, X. D.; He, W. Z.; Park, S. J.; Kim, H. K.; Hwang, Y. H. Solution-Derived $40 \mu \mathrm{m}$ Vertically Aligned $\mathrm{ZnO}$ Nanowire Arrays as Photoelectrodes in DyeSensitized Solar Cells. Nanotechnology 2010, 21, 195602.

(17) Xu, F.; Sun, L. T.; Dai, M.; Lu, Y. N. Fluorine-Ion-Mediated Electrodeposition of Rhombus-Like ZnFOH Nanorod Arrays: An Intermediate Route to Novel ZnO Nanoarchitectures. J. Phys. Chem. C 2010, 114, 15377-15382.

(18) Martinson, A. B. F.; Goes, M. S.; Fabregat-Santiago, F.; Bisquert, J.; Pellin, M. J.; Hupp, J. T. Electron Transport in Dye-Sensitized Solar Cells Based on ZnO Nanotubes: Evidence for Highly Efficient Charge Collection and Exceptionally Rapid Dynamics. J. Phys. Chem. A 2009, 113, 4015-4021.

(19) Wang, X. Y.; Tian, Z. P.; Yu, T.; Tian, H. M.; Zhang, J. Y.; Yuan, S. K.; Zhang, X. B.; Li, Z. S.; Zou, Z. G. Effective Electron Collection in Highly (110)-Oriented $\mathrm{ZnO}$ Porous Nanosheet Framework Photoanode. Nanotechnology 2010, 21, 065703.

(20) Lin, C. Y.; Lai, Y. H.; Chen, H. W.; Chen, J. G.; Kung, C. W.; Vittal, R; Ho, K. C. Highly Efficient Dye-Sensitized Solar Cell with A $\mathrm{ZnO}$ Nanosheet-Based Photoanode. Energy Environ. Sci. 2011, 4, 3448-3455.

(21) Lin, C. F.; Lin, H.; Li, J. B.; Li, X. Electrodeposition Preparation of $\mathrm{ZnO}$ Nanobelt Array Films and Application to Dye-Sensitized Solar Cells. J. Alloys Compd. 2008, 462, 175-180.

(22) Yodyingyong, S.; Zhang, Q. F.; Park, K.; Dandeneau, C. S.; Zhou, X. Y.; Triampo, D.; Cao, G. Z. ZnO Nanoparticles and Nanowire Array Hybrid Photoanodes for Dye-Sensitized Solar Cells. Appl. Phys. Lett. 2010, 96, 073115.

(23) Jiang, C. Y.; Sun, X. W.; Tan, K. W.; Lo, G. Q.; Kyaw, A. K. K.; Kwong, D. L. High-Bendability Flexible Dye-Sensitized Solar Cell with 
A Nanoparticle-Modified ZnO-Nanowire Electrode. Appl. Phys. Lett. 2008, 92, 143101.

(24) Xu, F.; Dai, M.; Lu, Y. N.; Sun, L. T. Hierarchical ZnO Nanowire-Nanosheet Architectures for High Power Conversion Efficiency in Dye-Sensitized Solar Cells. J. Phys. Chem. C 2010, 114, $2776-2782$.

(25) Qiu, J. H.; Guo, M.; Wang, X. D. Electrodeposition of Hierarchical $\mathrm{ZnO}$ Nanorod-Nanosheet Structures and Their Applications in Dye-Sensitized Solar Cells. ACS Appl. Mater. Interface 2011, 3, 2358-2367.

(26) Ko, S. H.; Lee, D.; Kang, H. W.; Nam, K. H.; Yeo, J. Y.; Hong, S. J.; Grigoropoulos, C. P.; Sung, H. J. Nanoforest of Hydrothermally Grown Hierarchical $\mathrm{ZnO}$ Nanowires for A High Efficiency DyeSensitized Solar Cell. Nano Lett. 2011, 11, 666-671.

(27) Listorti, A.; Oregan, B.; Durrant, J. R. Electron Transfer Dynamics in Dye-Sensitized Solar Cells. Chem. Mater. 2011, 23, 3381-3399.

(28) Novoselov, K. S.; Geim, A. K.; Morozov, S. V.; Jiang, D.; Zhang, Y.; Dubonos, S. V.; Grigorieva, I. V.; Firsov, A. A. Electric Field Effect in Atomically Thin Carbon Films. Science 2004, 306, 666-669.

(29) Hummers, W. S.; Offeman, R. E. Preparation of Graphitic Oxide. J. Am. Chem. Soc. 1958, 80, 1339-1339.

(30) Bi, H. C.; Yin, K. B.; Xie, X.; Zhou, Y. L.; Wan, N.; Xu, F.; Banhart, F.; Sun, L. T; Ruoff, R. S. Low Temperature Casting of Graphene with High Compressive Strength. Adv. Mater. 2012, 24, 5124-5129.

(31) Jezequel, D.; Guenot, J.; Jouini, N.; Fievet, F. Preparation and Morphological Characterization of Fine, Spherical, Monodisperse Particles of ZnO. Mater. Sci. Forum 1994, 152-153, 339-342.

(32) Wu, Z. C.; Chen, Z. H.; Du, X.; Logan, J. M.; Sippel, J.; Nikolou, M.; Kamaras, K.; Reynolds, J. R.; Tanner, D. B.; Hebard, A. F.; et al. Transparent, Conductive Carbon Nanotube Films. Science 2004, 305, $1273-1276$.

(33) Nethravathi, C.; Rajamathi, M. Chemically Modified Graphene Sheets Produced by The Solvothermal Reduction of Colloidal Dispersions of Graphite Oxide. Carbon 2008, 46, 1994-1998.

(34) Li, D.; Muller, M. B.; Gilje, S.; Kaner, R. B.; Wallace, G. G. Processable Aqueous Dispersions of Graphene Nanosheets. Nat. Nanotechnol. 2008, 3, 101-105.

(35) Li, X. L.; Zhang, G. Y.; Bai, X. D.; Sun, X. M.; Wang, X. R.; Wang, E. G.; Dai, H. J. Highly Conducting Graphene Sheets and Langmuir-Blodgett Films. Nat. Nanotechnol. 2008, 3, 538-542.

(36) Zhang, J. L.; Yang, H. J.; Shen, G. X.; Cheng, P.; Zhang, J. Y.; Guo, S. W. Reduction of Graphene Oxide Vial-Ascorbic Acid. Chem. Commun. 2010, 46, 1112-1114.

(37) Yang, N. L.; Zhai, J.; Wang, D.; Chen, Y. S.; Jiang, L. TwoDimensional Graphene Bridges Enhanced Photoinduced Charge Transport in Dye-Sensitized Solar Cells. ACS Nano 2010, 4, 887-894.

(38) Sun, S. R.; Gao, L.; Liu, Y. Q. Enhanced Dye-Sensitized Solar Cell Using Graphene- $\mathrm{TiO}_{2}$ Photoanode Prepared by Heterogeneous Coagulation. Appl. Phys. Lett. 2010, 96, 083113.

(39) Brown, P.; Takechi, K.; Kamat, P. V. Electrophoretic Deposition of CdSe- $\mathrm{C}_{60}$ Composite Films and Capture of Photogenerated Electrons with $n \mathrm{C}_{60}$ Cluster Shell. J. Phys. Chem. C 2008, 112, 4776-4782.

(40) Kongkanand, A.; Dominguez, R. M.; Kamat, P. V. Single Wall Carbon Nanotube Scaffolds for Photoelectrochemical Solar Cells. Capture and Transport of Photogenerated Electrons. Nano Lett. 2007, $7,676-680$.

(41) Chen, J.; Li, C.; Zhao, D. W.; Lei, W.; Zhang, Y.; Cole, M. T.; Chu, D. P.; Wang, B. P.; Cui, Y. P.; Sun, X. W.; Milne, W. I. A Quantum Dot Sensitized Solar Cell Based on Vertically Aligned Carbon Nanotube Templated ZnO Arrays. Electrochem. Commun. 2010, 12, 1432-1435.

(42) Kern, R.; Sastrawan, R.; Ferber, J.; Stangl, R.; Luther, J. Modeling and Interpretation of Electrical Impedance Spectra of Dye Solar Cells Operated under Open-Circuit Conditions. Electrochim. Acta 2002, 47, 4213-4225.
(43) Wang, M. K.; Chen, P.; Humphry-Baker, R.; Zakeeruddin, S. M.; Gratzel, M. The Influence of Charge Transport and Recombination on The Performance of Dye-Sensitized Solar Cells. ChemPhysChem 2009, 10, 290-299.

(44) Bisquert, J. Chemical Capacitance of Nanostructured Semiconductors: Its Origin and Significance for Nanocomposite Solar Cells. Phys. Chem. Chem. Phys. 2003, 5, 5360-5364.

(45) Choi, H. B.; Kang, S. O.; Ko, J.; Gao, G. H.; Kang, H. S.; Kang, M. S.; Nazeeruddin, M. K.; Gratzel, M. An Efficient Dye-Sensitized Solar Cell with An Organic Sensitizer Encapsulated in A Cyclodextrin Cavity. Angew. Chem., Int. Ed. 2009, 48, 5938-5941.

(46) Song, J. L.; Yin, Z. Y.; Yang, Z. J.; Amaladass, P.; Wu, S. X.; Ye, J.; Zhao, Y.; Deng, W. Q.; Zhang, H.; Liu, X. W. Enhancement of Photogenerated Electron Transport in Dye-Sensitized Solar Cells with Introduction of A Reduced Graphene Oxide- $\mathrm{TiO}_{2}$ Junction. Chem.Eur. J. 2011, 17, 10832-10837.

(47) Wang, X.; Zhi, L. J.; Mullen, K. Transparent, Conductive Graphene Electrodes for Dye-Sensitized Solar Cells. Nano Lett. 2008, $8,323-327$.

(48) Zhang, Y. Z.; Wu, L. H.; Liu, Y. P.; Xie, E. Q. Improvements to The Hierarchically Structured $\mathrm{ZnO}$ Nanosphere Based Dye-Sensitized Solar Cells. J. Phys. D: Appl. Phys. 2009, 42, 085105.

(49) Zheng, Y. Z.; Tao, X.; Hou, Q.; Wang, D. T.; Zhou, W. L.; Chen, J. F. Iodine-Doped $\mathrm{ZnO}$ Nanocrystalline Aggregates for Improved Dye-Sensitized Solar Cells. Chem. Mater. 2011, 23, 3-5. 